\title{
Effect of soil biodegradation on tensile and physical properties of coir/pineapple leaf fibre reinforced poly lactic acid hybrid biocomposites
}

\author{
Ramengmawii Siakeng, Mohammad Jawaid, Hidayah Ariffin, S. M. Sapuan
}

\begin{abstract}
Natural fibre and biopolymer based biocomposites are getting rising consideration owing to their renewability and biodegradation properties. In order to observe the behavior of these biocomposites in outdoor applications, its environmental reaction properties such as soil biodegradation need to be analyzed. In this study coir fibres (CF) and pineapple leaf fibres $(P A L F)$ reinforced polylactic acid (PLA) hybrid biocomposites (CF/PALF/PLA), pure PLA, pure CF (C30) and PALF (P30) biocomposites were fabricated through heat compounding and hot pressing methods. Effect of soil biodegradation on the tensile properties of PLA, CF and PALF biocomposites, and hybrid biocomposites were assessed and evaluated by Soil Burial tests. Tensile samples of all biocomposites undergoes soil burial test for 60 and 90 days at natural condition. After the subjected period, the results indicated that there is reduction in weight, tensile strength and modulus values of biocomposites owing to lignin degradation and fibre-matrix bonds.
\end{abstract}

Index Terms: Hybrid biocomposites; Polylactic acid; Soil burial; Tensile properties

\section{INTRODUCTION}

Natural fibres are favorable resources for industrial application, as they are environmentally efficient besides having high strength to weight ratio, biodegradability, renewability and sustainability [1]. They are potent carbon dioxide sequesters which shows their potential in mitigation of environmental pollution [2]. Synthetic fibre and polymer composites, on the other hand have prolonged life cycle which has negative environmental impact through excess-accumulation as well as soil and water pollution [3].

Revised Manuscript Received on July 05, 2019

R Siakeng, Institute of Tropical Forestry and Forest Products (INTROP), Universiti Putra Malaysia, Serdang, Selangor, Malaysia. Corresponding author.Email: ramengmawii8@gmail.com

M. Jawaid, Institute of Tropical Forestry and Forest Products (INTROP), Universiti Putra Malaysia, Serdang, Selangor, Malaysia. Corresponding author.Email: jawaid@upm.edu.my

H. Ariffin, Institute of Tropical Forestry and Forest Products (INTROP), Universiti Putra Malaysia, Serdang, Selangor, Malaysia.

S. M. Sapuan, Institute of Tropical Forestry and Forest Products (INTROP), Universiti Putra Malaysia, Serdang, Selangor, Malaysia.

Owing to their nature of biodegradability, natural fibres have been gradually more adopted to replace synthetic fibres in composites for various applications. Among the numerous natural fibres, coir fibres (CF) and pineapple leaf fibres (PALF) both shown a great prospective for use in biocomposite structures [4]. Additionally composites made from reinforcing natural fibres in biopolymers due to their numerous advantages have been a focus of many researches and they are environmentally eye-catching [5]. Biopolymers are biodegradable, renewable and eco-friendly polymers and they are increasingly more adopted to substitute synthetic polymers for industrial applications [6]. Polylactic acid (PLA) is one of the most researched biopolymer which possesses good physical and mechanical properties making it one of the best candidates for use as a matrix in natural fibre base composites [7]. Hybrid biocomposites are the biocomposites which are made of two or more reinforcements in one matrix or single reinforcement in polymer blends. Hybrid biocomposites possess unique properties which did not displayed by single fibre reinforced biocomposites [8].

Natural fibre hybrid biocomposites show good mechanical characteristics and have their advantages ecologically over their synthetic counterparts. On the other hand, the risk of degradation is higher in natural fibre biocomposites due to its constituents which restrict some of their application especially outdoor and engineering sectors [9]. The major constituents responsible for various types of biocomposites degradation are shown in Table 1. Hemicelluloses found to be the major accountable constituent for moisture and biological degradation while lignin is responsible for ultraviolet degradation. The strength of the fibres is controlled by crystalline cellulose, matrix (non-crystalline cellulose + hemicelluloses + lignin), and lignin[10]. The long-term environmental effects on natural fibre hybrid biocomposites be able to be evaluated by real time interpretation of the samples exposed to natural environmental conditions [11]. Usually, Soil burial test is carried out to establish durability of the material in contact with any type of soil. The idea is to examine the extent on biodegradability properties possessed by the composite materials when exposed to environmental conditions [12] This helps in the disposal and management of the materials. Chalking, yellowing, softening, cracking, brittleness and loss of transparency are common effects on conventional polymers and composites exposed to natural conditions [13].

Table. 1:Major constituents responsible for various types of degradation

\begin{tabular}{|c|c|c|}
\hline Biological & Thermal & Ultraviolet \\
\hline Degradation & Degradation & Degradation \\
\hline Hemicelluloses & Hemicelluloses & Lignin \\
\hline $\begin{array}{l}\text { Non-crystalline } \\
\text { cellulose }\end{array}$ & Cellulose & Hemicelluloses \\
\hline $\begin{array}{l}\text { Crystalline } \\
\text { cellulose }\end{array}$ & Lignin & $\begin{array}{l}\text { Non-crystalline } \\
\text { cellulose }\end{array}$ \\
\hline Lignin & & $\begin{array}{l}\text { Crystaline } \\
\text { cellulose }\end{array}$ \\
\hline $\begin{array}{l}\text { Researchers } \\
\text { effect of soil } \\
\text { on the characte } \\
\text { fibre Publishenfoy? }\end{array}$ & $\begin{array}{l}\text { cved the } \\
\text { egradation } \\
\text { cs of coir } \\
\text { PLA }\end{array}$ & \\
\hline
\end{tabular}


biocomposites for a short period. They concluded that the rate of biodegradation was enhanced by incorporation of coir fibres while its influence on the mechanical properties were not discussed [14]. In another interesting study, researchers carried out natural weathering and soil burial tests on kenaf fibre filled unsaturated polyester composites and reported no noteworthy effects on the mechanical properties of the soil buried samples due to low relative humidity [13]. In this study, the biodegradation of CF/PALF/PLA hybrid biocomposites are analyzed via soil burial experiments that imitate degradation in a biologically- active natural environment. The biodegradation of neat PLA was also examined so as to make comparisons with the composites.

\section{MATERIALS AND METHODS}

\section{a) Fibres and polymers}

Coir fibres $(\mathrm{CF})$ were obtained from Innovative Pultrusion Sdn Bhd. Malaysia with an average density of $1.20 \mathrm{~g} / \mathrm{cm} 3$. Pineapple leaf fibres (PALF) were delivered from Tamil Nadu state of South India which has an average density of $1.07 \mathrm{~g} / \mathrm{cm} 3$. All fibres were used in as-it is without any surface treatment. Polylactic acid (PLA) granules with a molecular weight $\left(M_{\mathrm{w}}\right)$ of approximately $74,000 \mathrm{~g} / \mathrm{mol}$, density of $1.25 \mathrm{~g} / \mathrm{mol}$, glass transition temperature $\left(T_{\mathrm{g}}\right)$ of 55 to $60^{\circ} \mathrm{C}$ and melting point $\left(T_{\mathrm{m}}\right)$ of 160 to $180^{\circ} \mathrm{C}$ was supplied by TT Biotechnologies Sdn. Bhd., Malaysia.

\section{b) Samples preparation}

Chopped CF and PALF fibres (1-2 mm) with 6-8\% moisture content were used for fabrication of biocomposites. CF/PALF/PLA biocomposites were formulated by melt mixing in a mixer Brabender Plasticizer. For all biocomposites, the mixing time was performed for $10 \mathrm{~min}$ at $180{ }^{\circ} \mathrm{C}$ temperature at a speed of $50 \mathrm{rpm}$. The nominal fibre content was set at $30 \%$ and PLA at $70 \%$ weight content in which specific fibre (CF:PALF) ratios were utilized for the hybrids. Henceforward, the ratios are referred to the fibres name where $\mathrm{C}$ stands for $\mathrm{CF}$ and $\mathrm{P}$ stands for PALF. Tthree types of hybrid biocomposites such as C3P7, C1P1, C7P3 and two types' single fibre composites, C30 and P30 were produced. The mixed samples were grinded by a mechanical grinder prior to pressing. Samples were transferred to a $15 \times 15 \times 3 \mathrm{~mm}$ metal plate mould and pressed by a hot press at $180^{\circ} \mathrm{C}$ for $10 \mathrm{~min}$ without pressure followed by 3 minutes with pressure. Then the moulds were detached and cooled to room temperature to obtain biocomposites sheets of thickness about 3mm. Biocomposites were cut based on characterizations such as rectangular strips for overall testing and dog-bone shaped for tensile tests.

\section{c) Characterization techniques}

\section{Tensile test}

Tensile strength and modulus of all the specimens of pure and hybrid biocomposites were measured before and after soil burial test. Tensile tests were carried out according to ASTM standards D $638-14$ by a $5 \mathrm{kN}$ Bluehill INSTRON Universal Testing Machine. The temperature and humidity were set at $22{ }^{\circ} \mathrm{C}$ and $50 \%$ respectively. The biocomposites were gripped at a $30 \mathrm{~mm}$ gauge length at a crosshead speed of $1.0 \mathrm{~mm} / \mathrm{min}$.

\section{Soil burial test}

Biodegradability tests of both neat PLA and CF/PALF/PLA biocomposites samples were carried out by a simple soil burial test method in order to determine the natural biodegradation of the biocomposites. The samples were in the form of a dog-bone shape (ASTM 638-14; Tensile samples) and were buried on natural soil in a flower pot without any composting materials. These burial pots were located in outdoor environment which have an average temperature and relative humidity of $30{ }^{\circ} \mathrm{C}$ and $80 \%$. The buried samples were removed periodically $(30,60,90,120$ and 150 days) for the characterization tests. After the burial time was finished, burial samples were washed by normal water to get rid of the soil debris and other unwanted materials from its surface. The samples were then air-dried indoor till the tests samples attain a constant weight. The biodegradation of the samples were assessed and evaluated by measuring each weight loss before and after soil burial as well as tensile test (ASTM 638-14). The biocomposites samples weight loss were calculated using the following relation:

Weight loss $(\%)=\left[\left(\mathrm{W}_{0^{-}}-\mathrm{W}_{1}\right) / \mathrm{W}_{0}\right] \times 100$

(1)

Where, $\mathrm{W}_{0}$ and $\mathrm{W}_{1}$ are the weights of samples before and after burial. Also the visual comparison was carried out by Image Analyzer through surface appearances of the composted samples.

\section{RESULT AND DISCUSSIONS}

\section{a) Tensile properties}

Result of tensile properties of PLA and biocomposites pre and pro soil burial tests are shown in table 2. Except for neat PLA, which shows almost no decrease all the biocomposites tensile strength's gradually decreased with time and were linear with the days of burial. Tensile strength is highest in P30 and C1P1 before soil burial test i.e, 21.86 MPa and 19.15 $\mathrm{MPa}$ respectively while lowest in 90 days buried sample of C1P1 (4.30 MPa) followed by C30 (5.42 MPa). Tensile modulus is highest in unburied $\mathrm{P} 30$ biocomposites i.e, 5.11 GPa while all the others biocomposites have tensile modulus in the range of 4-5 GPa. 90 days buried sample of $\mathrm{C} 30$ showed lowest tensile modulus $(0.65 \mathrm{GPa})$ while all the hybrid composites showed tensile modulus of average 1.8 $\mathrm{GPa}$ within the same burial time.

Table. 2:Tensile strength and modulus of PLA and CF/PALF/PLA hybrid biocomposites before and after soil burial tests.

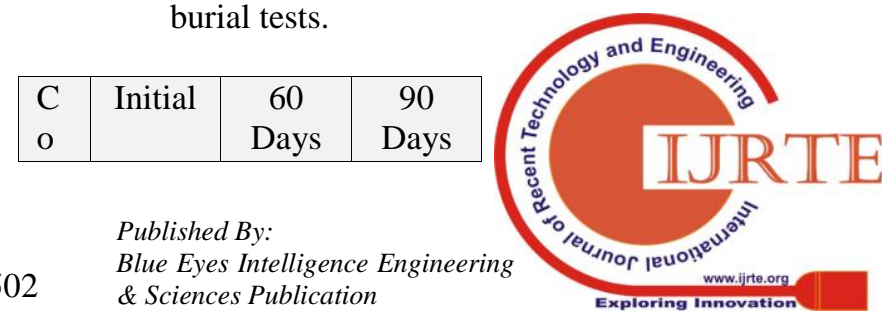




\begin{tabular}{|l|l|l|l|l|l|l|}
\hline $\mathrm{m}$ & $\mathrm{T}$ & $\mathrm{Y}$ & $\mathrm{T}$ & $\mathrm{Y}$ & $\mathrm{T}$ & $\mathrm{Y}$ \\
$\mathrm{p}$ & $\mathrm{e}$ & $\mathrm{o}$ & $\mathrm{e}$ & $\mathrm{o}$ & $\mathrm{e}$ & $\mathrm{o}$ \\
$\mathrm{os}$ & $\mathrm{n}$ & $\mathrm{u}$ & $\mathrm{n}$ & $\mathrm{u}$ & $\mathrm{n}$ & $\mathrm{u}$ \\
$\mathrm{it}$ & $\mathrm{si}$ & $\mathrm{n}$ & $\mathrm{si}$ & $\mathrm{n}$ & $\mathrm{si}$ & $\mathrm{n}$ \\
$\mathrm{e}$ & $\mathrm{le}$ & $\mathrm{g}$ & $\mathrm{le}$ & $\mathrm{g}$ & $\mathrm{le}$ & $\mathrm{g}$ \\
$\mathrm{S}$ & $\mathrm{st}$ & $\mathrm{s}$ & $\mathrm{st}$ & $\mathrm{s}$ & $\mathrm{st}$ & $\mathrm{s}$ \\
$\mathrm{a}$ & $\mathrm{re}$ & $\mathrm{m}$ & $\mathrm{re}$ & $\mathrm{m}$ & $\mathrm{re}$ & $\mathrm{m}$ \\
$\mathrm{m}$ & $\mathrm{n}$ & $\mathrm{o}$ & $\mathrm{n}$ & $\mathrm{o}$ & $\mathrm{n}$ & $\mathrm{o}$ \\
$\mathrm{pl}$ & - & $\mathrm{d}$ & - & $\mathrm{d}$ & - & $\mathrm{d}$ \\
$\mathrm{es}$ & $\mathrm{gt}$ & $\mathrm{ul}$ & $\mathrm{gt}$ & $\mathrm{ul}$ & $\mathrm{gt}$ & $\mathrm{ul}$ \\
$\mathrm{in}$ & $\mathrm{h}$ & $\mathrm{u}$ & $\mathrm{h}$ & $\mathrm{u}$ & $\mathrm{h}$ & $\mathrm{u}$ \\
$\mathrm{S}$ & ( & $\mathrm{s}$ & ( & $\mathrm{s}$ & ( & $\mathrm{s}$ \\
$\mathrm{oi}$ & $\mathrm{M}$ & $\mathrm{(}$ & $\mathrm{M}$ & $\mathrm{(}$ & $\mathrm{M}$ & ( \\
$\mathrm{l}$ & $\mathrm{P}$ & $\mathrm{G}$ & $\mathrm{P}$ & $\mathrm{G}$ & $\mathrm{P}$ & $\mathrm{G}$ \\
& $\mathrm{a})$ & $\mathrm{P}$ & $\mathrm{a}$ & $\mathrm{P}$ & $\mathrm{a}$ & $\mathrm{P}$ \\
& & $\mathrm{a})$ & & $\mathrm{a})$ & & $\mathrm{a})$ \\
\hline $\mathrm{P}$ & 1 & 3. & 1 & 3. & 1 & 2. \\
$\mathrm{~L}$ & 4. & 9 & 4. & 7 & 3. & 7 \\
$\mathrm{~A}$ & 6 & 8 & 1 & 6 & 6 & 6 \\
& 8 & & 0 & & 6 & \\
\hline $\mathrm{C}$ & 1 & 4. & 7. & 1. & 5. & 0. \\
3 & 3. & 3 & 2 & 2 & 4 & 6 \\
0 & 9 & 5 & 9 & 4 & 2 & 5 \\
& 6 & & & & & \\
\hline $\mathrm{P}$ & 2 & 5. & 1 & 2. & 1 & 2. \\
3 & 1. & 1 & 2. & 5 & 0. & 1 \\
0 & 8 & 1 & 0 & 9 & 6 & 1 \\
& 6 & & 3 & & 4 & \\
\hline $\mathrm{C}$ & 1 & 4. & 9. & 2. & 4. & 1. \\
1 & 9. & 7 & 6 & 1 & 3 & 9 \\
$\mathrm{P}$ & 1 & 5 & 2 & 8 & 0 & 4 \\
1 & 5 & & & & & \\
\hline $\mathrm{C}$ & 1 & 4. & 8. & 2. & 6. & 1. \\
3 & 3. & 4 & 6 & 2 & 6 & 6 \\
$\mathrm{P}$ & 2 & 5 & 1 & 8 & 1 & 3 \\
7 & 1 & & & & & \\
\hline $\mathrm{C}$ & 1 & 4. & 8. & 2. & 7. & 1. \\
7 & 4. & 4 & 6 & 0 & 6 & 8 \\
$\mathrm{P}$ & 3 & 7 & 1 & 7 & 1 & 0 \\
3 & 7 & & & & & \\
\hline & & & & & \\
\hline
\end{tabular}

\section{a) Degradation in soil}

It has been established that PLA degraded in soil although it is less susceptible to degradation in natural environment when compares to other aliphatic biodegradable polymers [15]. On the other hand, CF and PALF are easily degraded by soil microbes such as soil fungi and bacteria. So, the $\mathrm{CF}$ and PALF used as reinforcements in the composites would boost the degradation rate of the biocomposites. Natural fibres can reduced into simple biomass causing minimal damage to the soil ecosystem and environment in generals [14, 16].

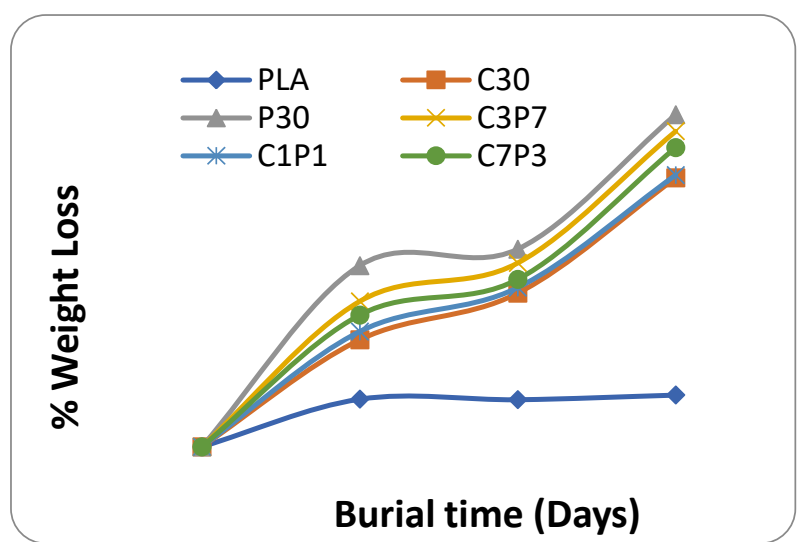

Fig. 1:Effects of soil degradation on \% weight loss of PLA and CF/PALF/PLA biocomposites

The level of biodegradability in the biocomposites and PLA samples were characterized by calculating the weight loss (\%) of each sample after 60- and 90-day's soil burial. Figure 1 depicted the percentage weight loss for CF/PALF/PLA biocomposites with varying fibre ratio loading along with neat PLA sample. Except for neat PLA, which shows almost no weight loss, all the biocomposites shows weight loss and were gradually degraded with time. The weight loss $(\%)$ in all the biocomposites samples was linear with the number of soil burial days. Approximately 1.9\% weight loss for neat PLA and weight losses of $9.8 \%$ and $12.1 \%$ for C30 and P30 biocomposites (Fig.1). Among the hybrid biocomposites C3P7 shows highest weight loss of $11.5 \%$ after 90 days burial time while $\mathrm{C} 1 \mathrm{P} 1$ had the least values over the same period.

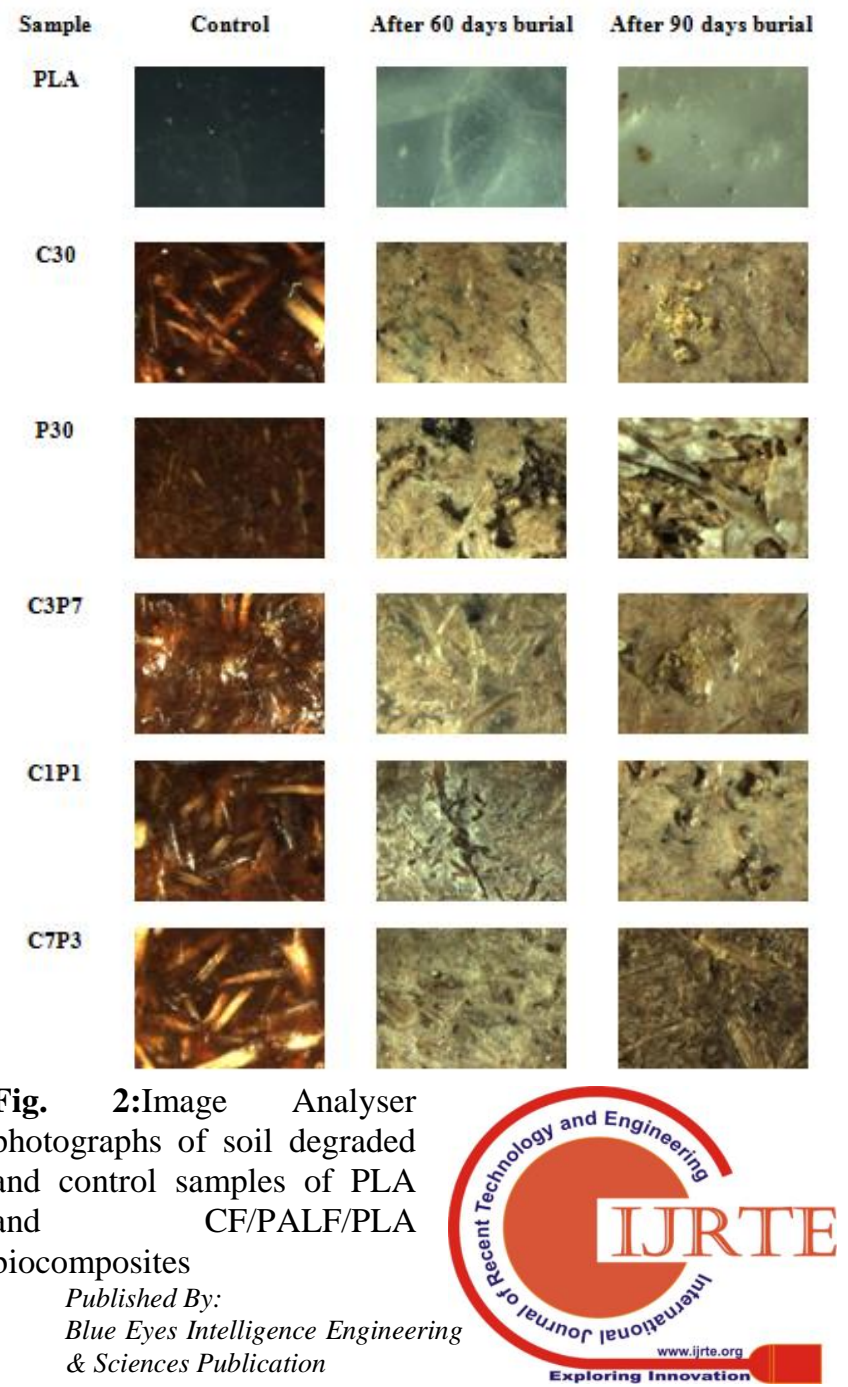




\section{Effect of soil biodegradation on tensile and physical properties of coir/pineapple leaf fibre reinforced poly lactic acid hybrid biocomposites}

Figure 2 depicted that the neat PLA sheet remain almost the same, there is no visible change in the original shape except for the loss of transparency due to the appearance of milky colour $[17,18]$. On the other hand, all the biocomposites crumbles, surfaces became rough and formed cracks and holes on the biocomposites surfaces as degradation proceeds. These cracks and holes were formed on account of fibres degradation [13]. Nevertheless, there are differences in the degree of biodegradation among the biocomposites. All these results are in accordance with the previous studies reported by many researchers in case of flax, kenaf and sisal fibre based PLA biocomposites exposed to soil burial weathering $[14,19-21]$. The burial process reduced the strength properties of the biocomposites which is attributed to polymer degradation and loss of adhesion/debonding between fibre and matrix.

\section{CONCLUSION}

The biodegradability of natural fibre/lignocellulosic fibre composites mainly depends on its polymer matrix. Many studies have shown that natural fibre composites are biodegradable if they are made up of a biodegradable polymer matrix. The chemical constituents of the natural fibres used as reinforcements also influences the biodegradability behaviour of the final composites. In addition, there are many other environmental factors which can influence the rate of biodegradation such as moisture, humidity, temperature and microbial population. The extended soil burial of the biocomposites dramatically decreased the tensile strengths, modulus and weight for all the biocomposites. Reduction is mainly attributed to matrix degradation and loss of adhesion between fibre and matrix. P30 shows highest tensile strength and young's modulus among all biocomposites after 90 days burial time. Among hybrid composites, C7P3 shows comparatively good young's modulus and best tensile strength after 90 days soil burial. The inclusion of PALF fairly improved the tensile properties of both pure CF and PLA matrix. This result shows a great possibility of hybrid CF/PALF/PLA biodegradable biocomposites applications in food packaging sector.

\section{ACKNOWLEDGEMENT}

The authors are thankful to the Ministry of Higher Education (Malaysia) for financial support (Commonwealth Scholarship and Fellowship Plan) of the first author's PhD study. The authors also wish to thank UPM for providing Putra grant GP-IPS /2017/9520200.

\section{REFERENCES}

[1] H.-y. Cheung, M.-p. Ho, K.-t. Lau, F. Cardona, and D. Hui. (2009). Natural fibre-reinforced composites for bioengineering and environmental engineering applications.Composites Part B: Engineering, Vol. 40, pp. 655-663, available online: https://doi.org/10.1016/j.compositesb.2009.04.014

[2] F. La Mantia and M. Morreale. (2011). Green composites: A brief review.Composites Part A: Applied Science and Manufacturing, Vol. 42, pp. 579-588, available online: https://doi.org/10.1016/j.compositesa.2011.01.017

[3] D. Jagadeesh, K. Kanny, and K. Prashantha. (2015). A review on research and development of green composites from plant protein-based polymers.Polymer Composites, Vol. 38, (8), pp 1504-1518, available online: https://doi.org/10.1002/pc.23718

[4] W. Wang and G. Huang.(2009). Characterisation and utilization of natural coconut fibres composites," Materials \& Design, Vol. 30, pp. 2741-2744, available online: https://doi.org/10.1016/j.matdes.2008.11.002

[5] S. Butylina, M. Hyvärinen, and T. Kärki. (2012). Accelerated weathering of wood-polypropylene composites containing minerals.Composites Part A: Applied Science and Manufacturing, Vol. 43, pp. 2087-2094, available online: https://doi.org/10.1016/j.compositesa.2012.07.003

[6] H. Gu. (2009). Tensile behaviours of the coir fibre and related composites after $\mathrm{NaOH}$ treatment.Materials \& Design, Vol. 30, pp 3931-3934, available https://doi.org/10.1016/j.matdes.2009.01.035

[7] R. Siakeng, M. Jawaid, H. Ariffin, S. Sapuan, M. Asim, and N. Saba Natural fiber reinforced polylactic acid composites: A review.Polymer Composites. early view (online version), available online: https://doi.org/10.1002/pc.24747

[8] M. Asim, M. Jawaid, K. Abdan, M. Ishak, and O. Alothman. (2018). Effect of Hybridization on the Mechanical Properties of Pineapple Leaf Fiber/Kenaf Phenolic Hybrid Composites.Journal of Renewable Materials,Vol.6, no.1, (9), pp.38-46, available online: https://doi.org/10.7569/JRM.2017.634148

[9] M. S. Islam, K. L. Pickering, and N. J. Foreman. (2010). Influence of accelerated ageing on the physico-mechanical properties of alkali-treated industrial hemp fibre reinforced poly (lactic acid)(PLA) composites.Polymer Degradation and Stability, Vol. 95, pp. 59-65, available https://doi.org/10.1016/j.polymdegradstab.2009.10.010

[10] M. Jawaid, N. Saba, O. Alothman, and M. Paridah. (2016). Effect of accelerated environmental aging on tensile properties of oil palm/jute hybrid composites.AIP Conference Proceedings, Vol. 040007, pp.1787, available online: http:dx.doi.org/10.1063/1.4968086

[11] M. D. H. Beg and K. L. Pickering. (2008). Accelerated weathering of unbleached and bleached Kraft wood fibre reinforced polypropylene composites.Polymer Degradation and Stability, Vol. 93, pp. 1939-1946, available online: https://doi.org/10.1016/j.polymdegradstab.2008.06.012

[12]Z. Azwa, B. Yousif, A. Manalo, and W. Karunasena. (2013). A review on the degradability of polymeric composites based on natural fibres.Materials \& Design, Vol. 47, pp. 424-442, available online: https://doi.org/10.1016/j.matdes.2012.11.025

[13] A. Rashdi, S. Sapuan, M. Ahmad, and A. Khalina. (2010). Combined Effects of Water Absorption Due to Water Immersion, Soil Buried and Natural Weather on Mechanical Properties Of Kenaf Fibre Unsaturated Polyester Composites (KFUPC).International Journal of Mechanical and Materials Engineering, Vol. 5, pp. 11-17.

[14] Y. Dong, A. Ghataura, H. Takagi, H. J. Haroosh, A. N. Nakagaito, and K.-T. Lau. (2014). Polylactic acid (PLA) biocomposites reinforced with coir fibres: Evaluation of mechanical performance and multifunctional properties.Composites Part A: Applied Science and Manufacturing, Vol. 63, pp. 76-84, available online: https://doi.org/10.1016/j.compositesa.2014.04.003

[15] T. Ohkita and S. H. Lee. (2006).Thermal degradation and biodegradability of poly (lactic acid)/corn starch biocomposites.Journal of Applied Polymer Science, Vol. 100, pp. 3009-3017, available online: https://doi.org/10.1002/app.23425

[16] A. S. Harmaen, A. Khalina, I. Azowa, M. A. Hassan, A. Tarmian, and M. Jawaid. (2015). Thermal and biodegradation properties of poly (lactic acid)/fertilizer/oil palm fibers blends biocomposites.Polymer Composites, Vol. 36, pp. 576-583, available online: http ://doi.org/10.1002/pc.22974

[17]E. Rudnik and D. Briassoulis. (2011). Degradation behaviour of poly (lactic acid) films and fibres in soil under Mediterranean field conditions and laboratory simulations testing.Industrial Crops and Products, Vol. 33, pp. 648-658, available online: https://doi.org/10.1016/j.indcrop.2010.12.031

[18] A. Yussuf, I. Massoumi, and A. Hassan. (2010). Comparison of polylactic acid/kenaf and polylactic acid/rise husk composites: the influence of the natural fibers on the mechanical, thermal and biodegradability properties.Journal of Polymers and the Environment, Vol. 18, pp. 422-429, available online: https://doi.org/10.1007/s10924-010-0185-0

[19] R. Kumar, M. Yakubu, and R. Anandjiwala. (2010). Biodegradation of flax fiber reinforced poly lactic acid.eXPRESS Polymer Letters, Vol. 4(7), pp 423-430

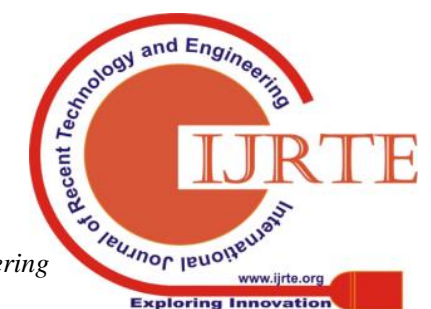


,available online: http://hdl.handle.net/10204/4093

[20] S. Alimuzzaman, R. H. Gong, and M. Akonda. (2014). Biodegradability of nonwoven flax fiber reinforced polylactic acid biocomposites.Polymer composites, Vol. 35, pp. 2094-2102, available online: https://doi.org/10.1002/pc.22871

[21]G. Rajesh, A. R. Prasad, and A. Gupta. (2015). Mechanical and degradation properties of successive alkali treated completely biodegradable sisal fiber reinforced poly lactic acid composites," Journal of Reinforced Plastics and Composites, Vol. 34, pp. 951-961, available online: https://doi.org/10.1177/0731684415584784

\section{AUTHORS PROFILE}

R. Siakeng completed doctorate degree in Bio-composites Technology and Design from Institute of Tropical Forestry and Forest Products (INTROP), Universiti Putra Malaysia. She has published10articles in international journals, book chapters and proceedings.

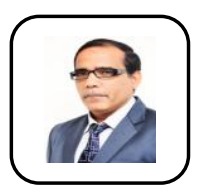

M. Jawaid is currently working as Fellow Researcher at Institute of Tropical Forestry and Forest Products (INTROP), Universiti Putra Malaysia.His area of expertise is polymer science. he has published 8 books, 25 book chapters, and more than 250 International journal papers.

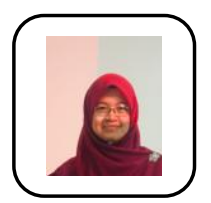

Hidayah Ariffin is associate professor and deputy director in Institute of Tropical Forestry and Forest Products (INTROP), University Putra Malaysia. Her area of expertise is biotechnology. She has published 150 articles in international journals, book chapters and proceedings.

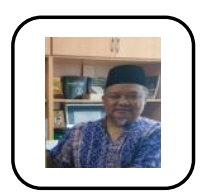

Sapuan Salit is professor in faculty of Engineering, University Putra Malaysia. Her area of expertise is mechanical engineering. She has published 300 articles in international journals, book chapters and proceedings. 